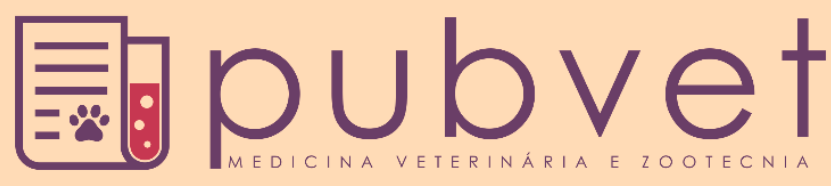

https://doi.org/10.31533/pubvet.v13n5a321.1-15

\title{
Produtividade de capim Paiaguás sob doses de nitrogênio e cortes
}

\author{
Diego do Nascimento ${ }^{1}$, Marice Cristine Vendruscolo ${ }^{2 *}$, Alessandro Bandeira Dalbianco ${ }^{1}$, \\ Diego Fernando Daniel ${ }^{10}$
}

${ }^{1}$ Graduando em Agronomia, Universidade do Estado de Mato Grosso - UNEMAT, Tangará da Serra, MT, Brasil.

${ }^{2}$ Professora da Universidade do Estado de Mato Grosso - UNEMAT, Departamento de Agronomia, Tangará da Serra, MT, Brasil.

*Autora para correspondência: e-mail: maricevendruscolo@yahoo.com.br

Resumo. O objetivo deste trabalho foi avaliar a produção de massa seca e outras características agronômicas da Brachiaria brizantha cv. Paiaguás em diferentes doses de nitrogênio $(\mathrm{N})$, no terceiro ano de produção. O experimento foi realizado na Universidade do Estado de Mato Grosso, em Tangará da Serra - MT, Brasil. O delineamento experimental foi em blocos casualizados (DBC), com seis tratamentos $(0,50,100,150,200$ e $250 \mathrm{~kg} / \mathrm{ha}$ de N) e quatro repetições. Foram realizados quatro cortes e analisadas as variáveis altura de plantas (AP), número de perfilhos $/ \mathrm{m}^{2}$ (NP), número de folhas/perfilho (NFP), massa seca/perfilho (MSP), porcentagem de massa seca (\%MS), relação folha: colmo (RFC), produção de massa verde/ha (MV), produção de massa seca/ha (MS), massa seca de folhas/ha (MSF), massa seca de colmos/ha (MSC) e massa seca de material senescente/ha (MSMS). Os dados foram submetidos à análise de variância pelo teste $\mathrm{F}$ e, ao apresentarem significância, foi realizada a análise de regressão, com o programa ASSISTAT. A altura de plantas, número de perfilhos $/ \mathrm{m}^{2}$, massa verde e massa seca/ha, massa seca de folhas, massa seca de colmos e massa seca de material senescente/ha do capim Paiaguás, diferiram estatisticamente e aumentaram com a adição das doses de nitrogênio até valores próximos a $250 \mathrm{~kg} / \mathrm{ha}$ de $\mathrm{N}$. A porcentagem de massa seca reduziu com o aumento das doses de nitrogênio. As variáveis número de folhas/perfilho, massa seca/perfilho e relação folha: colmo não responderam às doses de $\mathrm{N}$. Assim, conclui-se que as doses de nitrogênio incrementam significativamente as características produtivas da $B$. brizantha $\mathrm{cv}$. Paiaguás, no terceiro ano de produção, tendo resultados satisfatórios na dose de $200 \mathrm{~kg} / \mathrm{ha}$ de $\mathrm{N}$.

Palavras chave: adubação nitrogenada, forragem, gramínea, massa seca, pastagem

\section{Productivity of Paiaguás grass under nitrogen doses and cuts}

Abstract. The objective of this work was to evaluate the dry mass production and other agronomic characteristics of Brachiaria brizantha cv. Paiaguás in different doses of nitrogen $(\mathrm{N})$, in the third year of production. The experiment was carried out at the State University of Mato Grosso, in Tangará da Serra - MT, Brazil. The experimental design was randomized blocks (DBC), with six treatments $(0,50,100,150,200$ and $250 \mathrm{~kg} / \mathrm{ha}$ of N) and four replications. Four cuts were performed and analyzed the variables plant height (AP), number of tillers/m² (NP), dry mass/tiller (MSP), number of leaves/tiller (NFP), percentage of dry mass (\%MS), leaf ratio: high (RFC), production of green mass/ha (MV), production of dry mass/ha (MS), dry mass of leaves/ha (MSF), dry mass of stems/ha (MSC), dry mass of senescent material/ha (MSMS). Data were submitted to analysis of variance by the $\mathrm{F}$ test and, when they showed significance, the regression analysis was performed with the ASSISTAT program. Plant height, number of tillers $/ \mathrm{m}^{2}$, green mass and dry mass/ha, leaf dry mass, stems dry mass and dry mass of senescent material/ha of Paiaguás grass, differed statistically and increased with the addition of nitrogen doses up 
to $250 \mathrm{~kg} / \mathrm{ha}$ of $\mathrm{N}$. The percentage of dry mass reduced with the increase of the nitrogen doses. The variables number of leaves/tiller, dry mass/tiller and leaf ratio: high did not respond to the doses of $\mathrm{N}$. Thus, it is concluded that nitrogen doses significantly increase the productive characteristics of $B$. brizantha $\mathrm{cv}$. Paiaguás, in the third year of production, with satisfactory results in the dose of $200 \mathrm{~kg} / \mathrm{ha}$ of $\mathrm{N}$.

Keywords: nitrogen fertilization, forage, grass, dry mass, pasture

\section{Productividad de pasto Paiaguás bajo dosis de nitrógeno y cortes}

Resumen. El objetivo de este trabajo fue valuar la producción de masa seca y otras características agronómicas de la Brachiaria brizantha cv. Paiaguás en diferentes dosis de nitrógeno $(\mathrm{N})$, en el tercer año de producción. El experimento fue realizado en la Universidad del Estado de Mato Grosso, en Tangará da Serra - MT, Brasil. El diseño experimental fue en bloques casualizados (DBC), con seis tratamientos $(0,50,100,150$, 200 y $250 \mathrm{~kg} / \mathrm{ha}$ de N) y cuatro repeticiones. Se realizaron cuatro cortes y se analizaron las variables altura de plantas (AP), número de macollos $/ \mathrm{m}^{2}$ (NP), número de hojas/macollo (NFP), masa seca/macollo (MSP), porcentaje de masa seca (\%MS), relación hoja: tallo (RHT), producción de masa verde/ha (MV), producción de masa seca/ha (MS), masa seca del hojas/ha (MSH), masa seca del tallos/ha (MSC) y masa seca del material senescente/ha (MSMS). Los datos fueron sometidos al análisis de varianza por la prueba $\mathrm{F} \mathrm{y}$, al presentar significancia, se realizó el análisis de regresión, con el programa ASSISTAT. La altura de las plantas, número de macollos $/ \mathrm{m}^{2}$, masa verde y masa seca/ha, masa seca de hojas, masa seca de tallos y masa seca de material senescente/ha del pasto Paiaguás, difirieron estadísticamente y aumentaron con la adición de las dosis de nitrógeno hasta valores cercanos a $250 \mathrm{~kg} / \mathrm{ha}$ de $\mathrm{N}$. El porcentaje de masa seca redujo con el aumento de las dosis de nitrógeno. Las variables número de hojas/macollo, masa seca/macollo y relación hoja: tallo no respondieron a las dosis de $\mathrm{N}$. Así, se concluye que las dosis de nitrógeno incrementan significativamente las características productivas de la $B$. brizantha $\mathrm{cv}$. Paiaguás en el tercer año de producción, con resultados satisfactorios en la dosis de 200 $\mathrm{kg} / \mathrm{ha}$ de $\mathrm{N}$.

Palabras clave: fertilización nitrogenada, forraje, gramínea, masa seca, pasto

\section{Introdução}

Como principal fonte de alimento para os bovinos, as gramíneas forrageiras são usadas no Brasil para a criação em sistema extensivo, em pelo menos uma das fases de crescimento. A não utilização de técnicas que aprimorem os sistemas de produção é um grande empecilho no setor pecuário (Pimenta, 2009; Prado, 2010).

As gramíneas do gênero Brachiaria ocupam espaços cada vez maiores na pecuária brasileira, por serem plantas pouco exigentes às condições edafoclimáticas e os solos escolhidos para pastagens geralmente apresentam sérias limitações quanto à fertilidade química natural, acidez e topografia (Brighenti et al., 2012). A forrageira Brachiaria brizantha cv. Paiaguás vem ganhando espaço nas áreas destinadas ao cultivo de pastagens por ser considerada produtiva, ter maior acúmulo de folhas e maior tolerância a solos com má drenagem (Pimenta, 2009). Possui boa produtividade, vigor, produção de sementes e tem elevado potencial de produção animal no período seco, com alto teor de folhas e bom valor nutritivo. Apresenta maior acúmulo de forragem no período de seca, em relação a outras forrageiras, com um melhor valor nutritivo, resultando em maiores ganhos de peso por animal e por área (Euclides et al., 1998; Rezende et al., 2011). Além de verificar a adaptação de novas cultivares, tem-se a necessidade de realizar estudos relacionados à exigência nutricional destas plantas melhoradas e a definição de doses de nitrogênio recomendadas. Dentre os nutrientes essenciais, o nitrogênio tem maior impacto na produtividade das gramíneas forrageiras (Primavesi et al., 2004; Primavesi et al., 2006). De acordo com Fagundes et al. (2005), o suprimento de nitrogênio no solo normalmente não atende à demanda das gramíneas, porém, quando há adubação nitrogenada, são observadas grandes alterações na taxa de acúmulo de massa seca da forragem ao longo das estações do ano. 
O objetivo deste trabalho foi avaliar as características produtivas de $B$. brizantha cv. Paiaguás em diferentes doses parceladas de nitrogênio, no terceiro ano de produção.

\section{Material e métodos}

O experimento foi realizado na área experimental da Universidade do Estado de Mato Grosso (UNEMAT), Campus Universitário de Tangará da Serra, localizado nas coordenadas geográficas $14^{\circ} 39^{\prime} 53^{\prime \prime} \mathrm{S}, 57^{\circ} 25^{\prime} 46^{\prime \prime} \mathrm{O}$, com altitude de $440 \mathrm{~m}$. O clima é equatorial tropical, com temperatura média anual variando entre 24,4 e $26,1^{\circ} \mathrm{C}$ e precipitação média anual variando de $1.260,1$ a $1.815,5 \mathrm{~mm}$ (Dallacort et al., 2011). Os dados climáticos durante a execução do experimento estão apresentados nas Figuras 1 e 2.

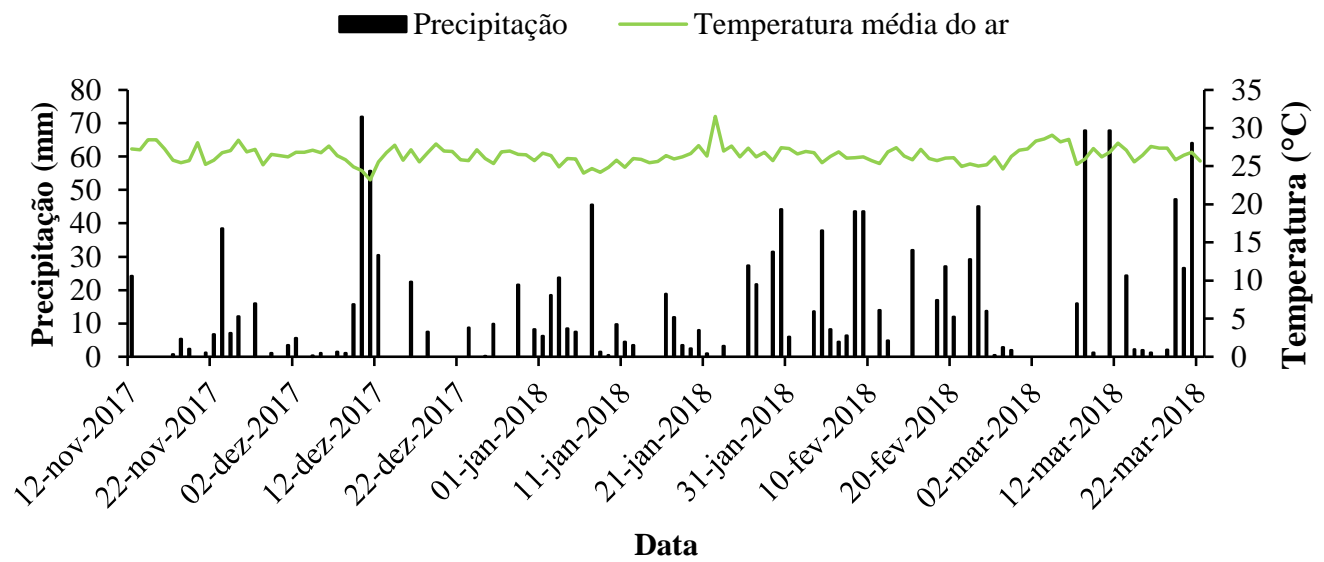

Figura 1. Comportamento diário da precipitação $(\mathrm{mm})$ e da temperatura média do $\operatorname{ar}\left({ }^{\circ} \mathrm{C}\right)$ no período experimental, entre 12/11/2017 e 22/03/2018. Fonte: Dados do INMET (Instituto Nacional de Meteorologia).

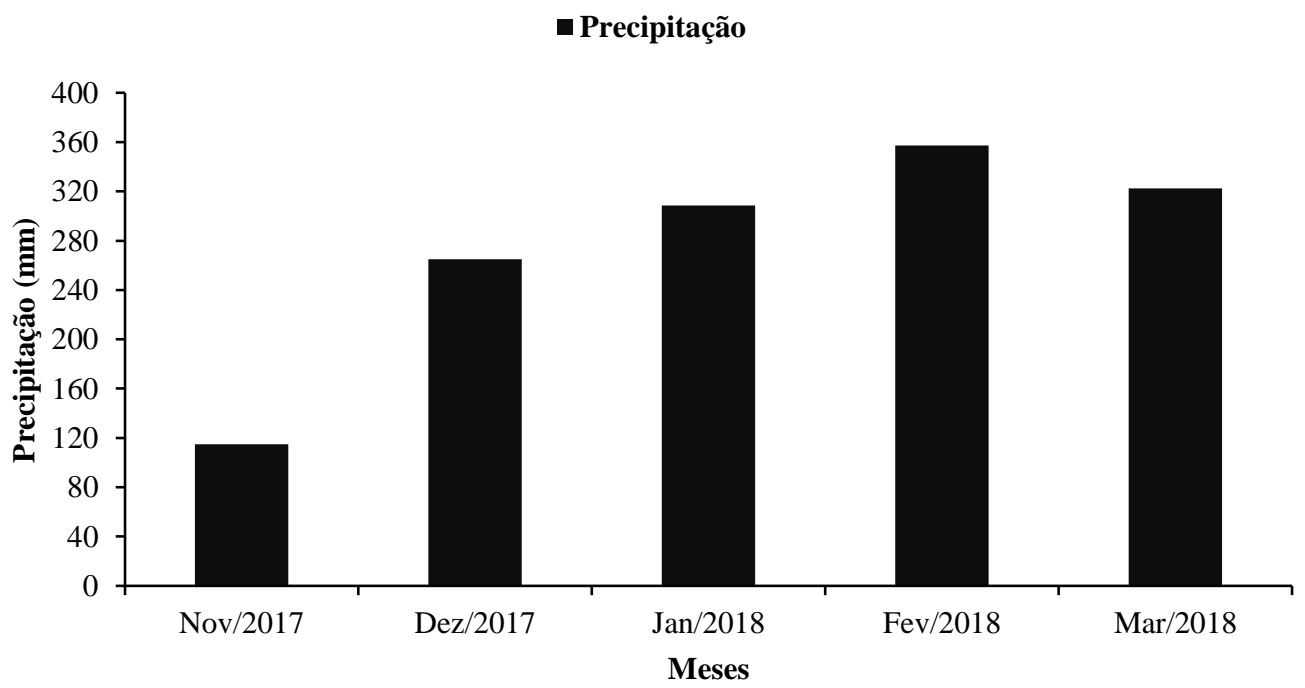

Figura 2. Precipitação mensal (mm) nos meses de condução do experimento, de novembro de 2017 a março de 2018. Fonte: Dados do INMET (Instituto Nacional de Meteorologia).

O experimento foi conduzido em área com B. brizantha cv. Paiaguás, cultivada em março de 2015, a fim de avaliar suas características produtivas no terceiro ano de produção. O corte de uniformização foi realizado a $0,25 \mathrm{~m}$ do nível do solo, no dia 12 de novembro de 2017, com a utilização de roçadora manual e realizada a coleta de sub-amostras de solo, na profundidade de $0-20 \mathrm{~cm}$, para compor a amostra em que foram analisadas as características químicas do solo (Tabela 1). 
Tabela 1. Características químicas do solo na profundidade de 0 - $20 \mathrm{~cm}$ na área experimental da Universidade do Estado de Mato Grosso (UNEMAT), em Tangará da Serra - MT

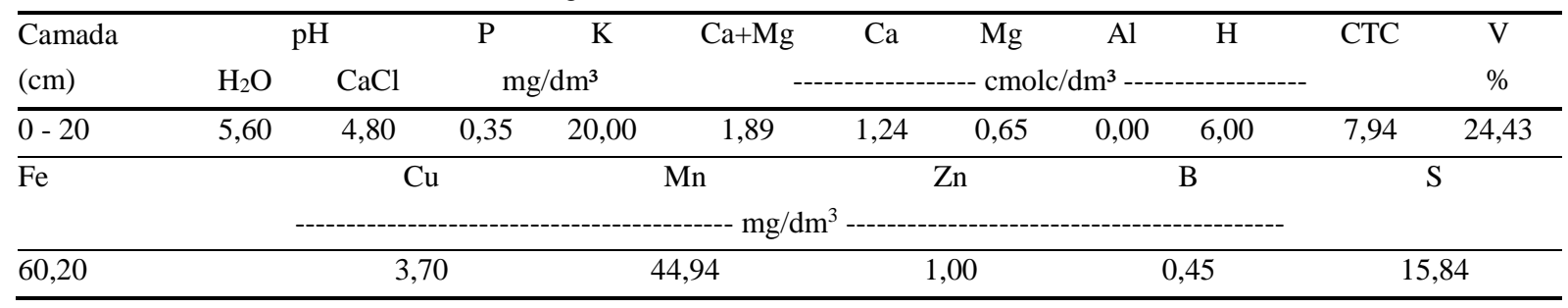

O delineamento experimental foi em blocos casualizados (DBC), com a espécie B. brizantha cv. Paiaguás, contendo seis tratamentos constando de diferentes doses de nitrogênio $(0,50,100,150,200$ e $250 \mathrm{~kg} / \mathrm{ha}$ de N) com quatro repetições, totalizando 24 parcelas, sendo cada parcela de $3 \mathrm{~m} \mathrm{x} 3 \mathrm{~m}\left(9 \mathrm{~m}^{2}\right)$ e foi desprezado $0,5 \mathrm{~m}$ dos quatro lados da parcela, devido ao efeito de bordadura, com isso, a área útil da parcela foi de $4 \mathrm{~m}^{2}$.

Foi realizada calagem e adubação a lanço, com cloreto de potássio e superfosfato triplo, na área de cada parcela, no dia 20 de novembro de 2017, conforme os resultados da análise do solo (Tabela 1). No dia 23 de novembro de 2017 foi realizado um novo corte de rebaixamento a $0,25 \mathrm{~m}$ do solo, sendo que logo após, a forragem cortada foi removida para fora das parcelas. No mesmo dia foi aplicada a primeira parcela da dose de nitrogênio de cada tratamento, na forma de ureia, sendo que a adubação nitrogenada foi parcelada em quatro aplicações, realizada imediatamente após os cortes, a cada 28 dias.

O primeiro corte para a avaliação das características produtivas do capim Paiaguás foi realizado no dia 21 de dezembro de 2017, o segundo corte foi no dia 17 de janeiro de 2018, o terceiro corte do capim foi realizado no dia 15 de fevereiro de 2018 e o quarto corte no dia 18 de março de 2018.

As variáveis quantitativas analisadas para os diferentes tratamentos foram altura de planta, número de perfilhos $/ \mathrm{m}^{2}$, número de folhas/perfilho, massa seca/perfilho, porcentagem de massa seca, relação folha: colmo, produção de massa verde e seca/ha, produção de folhas, colmos e material senescente/ha. A altura do pasto foi avaliada no dia de cada corte, fazendo-se 10 medições por parcela, com o auxílio de uma fita métrica. Foi considerada a altura da lâmina mais alta do dossel, a partir do nível do solo (Cecato et al., 2001).

$\mathrm{Na}$ área útil foi colocado um quadrado metálico medindo $0,5 \mathrm{~m} \mathrm{x} 0,5 \mathrm{~m}$ e as plantas que se encontravam dentro de cada quadrado foram cortadas a $0,25 \mathrm{~m}$ acima do nível do solo para a determinação da produção de massa verde através de pesagem. Retirou-se uma sub-amostra do material colhido de cada parcela, que foi pesada e colocada em saco plástico identificado. Em seguida, realizouse a separação de colmo e folha (altura da lígula) e material senescente. Depois de separadas, foram colocadas em sacos de papel previamente identificados, pesadas com a utilização de balança de precisão e colocadas em estufa com circulação forçada de ar a $55^{\circ} \mathrm{C}$ até atingir massa constante e pesadas novamente para determinação da massa seca (Cano et al., 2004).

Os perfilhos foram quantificados pela contagem direta dos mesmos, que foram amostrados dentro do quadrado metálico de $0,5 \mathrm{~m}$ x $0,5 \mathrm{~m}$. O número de folhas/perfilho foi obtido através da contagem direta da quantidade de folhas contidas em 20 perfilhos coletados aleatoriamente, ao nível do solo, em cada parcela. Após, os 20 perfilhos foram pesados e colocados em estufa com circulação forçada de ar a $55^{\circ} \mathrm{C}$ até atingir massa constante e pesados novamente para determinação da massa seca/perfilho.

Os dados dos componentes de produção foram submetidos à análise de variância (ANOVA) pelo teste $\mathrm{F}$ e, ao apresentarem significância foi realizada análise de regressão. O software utilizado foi o programa estatístico ASSISTAT versão 7.7, 2014 (Silva, 2014).

\section{Resultados e discussão}

Na Tabela 2 estão apresentados os valores médios de cada variável, no seu respectivo corte e se houve ou não diferença significativa nas diferentes doses de nitrogênio $(\mathrm{N})$. 
Tabela 2. Média da altura de plantas (AP), do número de perfilhos $/ \mathrm{m}^{2}$ (NP), do número de folhas/perfilho (NFP), da massa seca/perfilho (MSP), da porcentagem de massa seca (\%MS) e da relação folha: colmo (RFC) de B. brizantha cv. Paiaguás em diferentes doses de nitrogênio em Tangará da Serra - MT.

\begin{tabular}{lcccccc}
\hline Corte & $\mathrm{AP}(\mathrm{m})$ & $\mathrm{NP}\left(\mathrm{m}^{2}\right)$ & $\mathrm{NFP}$ & $\mathrm{MSP}(\mathrm{g})$ & $\% \mathrm{MS}$ & $\mathrm{RFC}$ \\
\hline $1^{\mathrm{o}}$ & $0,51^{* *}$ & $357,17^{* *}$ & $4,05^{\mathrm{ns}}$ & $0,61^{\mathrm{ns}}$ & $16,96^{\mathrm{ns}}$ & $2,34^{\mathrm{ns}}$ \\
$2^{\mathrm{o}}$ & $0,55^{* *}$ & $106,50^{\mathrm{ns}}$ & $4,13^{\mathrm{ns}}$ & $0,53^{\mathrm{ns}}$ & $28,49^{\mathrm{ns}}$ & $4,53^{\mathrm{ns}}$ \\
$3^{\mathrm{o}}$ & $0,51^{* *}$ & $104,67^{* *}$ & $3,92^{\mathrm{ns}}$ & $0,52^{\mathrm{ns}}$ & $20,41^{* *}$ & $4,21^{\mathrm{ns}}$ \\
$4^{\mathrm{o}}$ & $0,48^{* *}$ & $427,00^{*}$ & $5,09^{\mathrm{ns}}$ & $0,89^{\mathrm{ns}}$ & $25,05^{\mathrm{ns}}$ & $3,00^{\mathrm{ns}}$ \\
\hline
\end{tabular}

${ }^{\mathrm{ns}}$ não significativo; * significativo a $5 \%$; ** significativo a $1 \%$.

Observou-se que a altura de plantas (AP) apresentou diferença significativa entre as doses de $\mathrm{N}$ em todos os cortes (Tabela 2), obtendo resultados semelhantes. Para o número de perfilhos $/ \mathrm{m}^{2}(\mathrm{NP})$, apenas o segundo corte não apresentou diferença significativa entre as doses de N. O número de folhas/perfilho (NFP), a massa seca/perfilho (MSP) e a relação folha: colmo (RFC) não apresentaram diferença entre as doses de $\mathrm{N}$ em nenhum dos cortes avaliados. A variável porcentagem de massa seca (\%MS) apresentou diferença entre as doses de $\mathrm{N}$ apenas no terceiro corte (Tabela 2).

$\mathrm{O}$ valor máximo de altura das plantas, no primeiro corte ocorreu com a dose de $\mathrm{N}$ de $250 \mathrm{~kg} / \mathrm{ha}$, proporcionando uma altura de plantas de $0,69 \mathrm{~m}$ (Figura 3a) e a regressão linear indica que, aumentando a dose de N, poderá aumentar a altura de plantas.

(a)
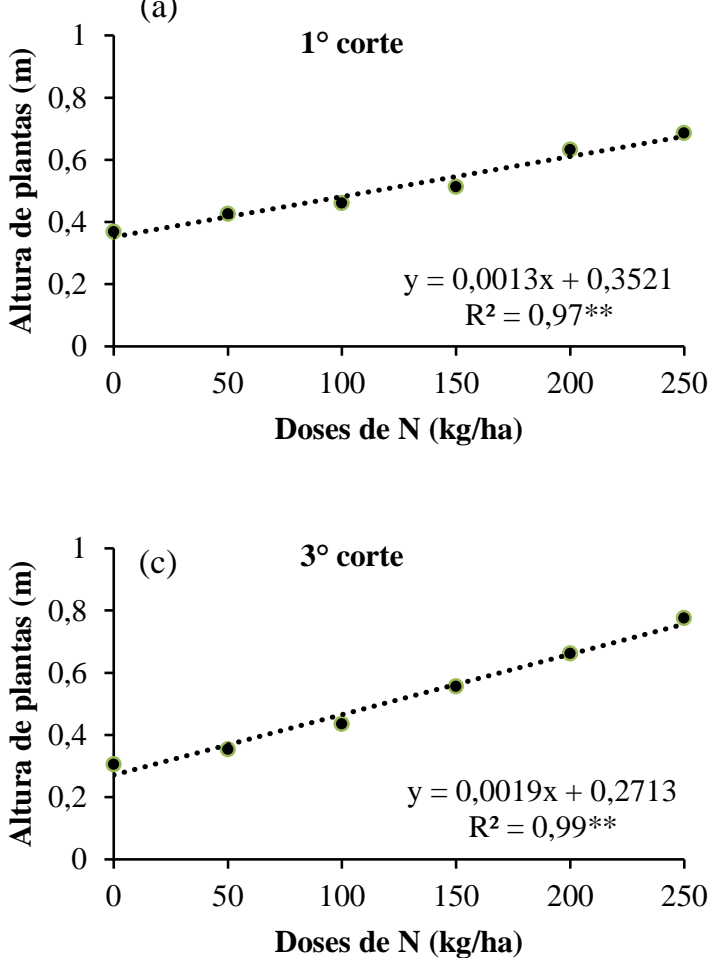

(b)
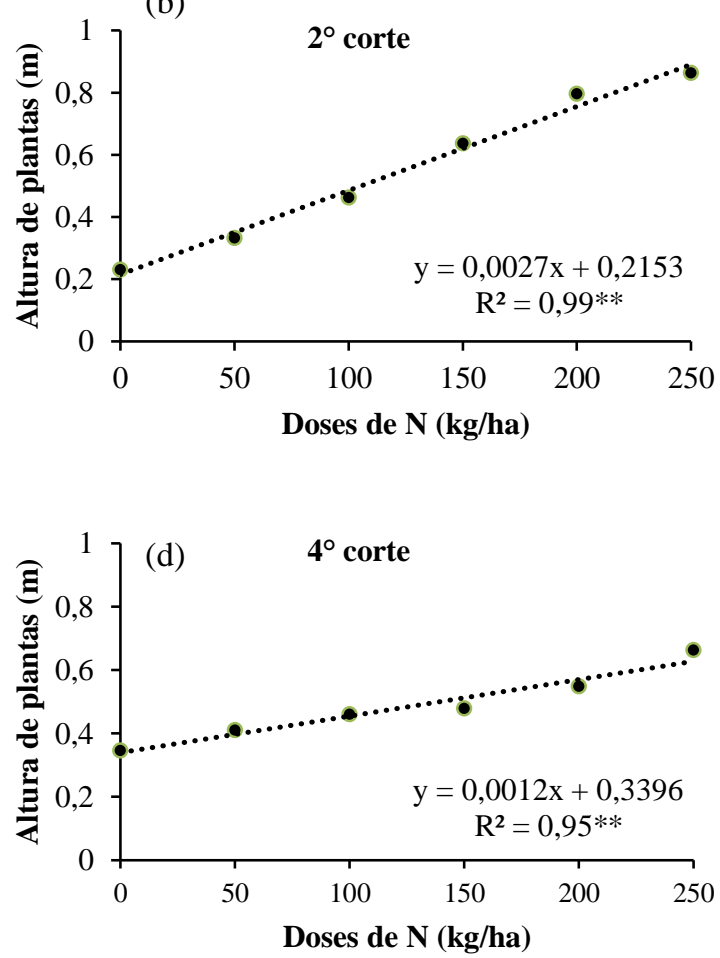

Figura 3. Altura de plantas (AP, m) no primeiro (a), segundo (b), terceiro (c) e quarto cortes (d) de B. brizantha cv. Paiaguás em diferentes doses de nitrogênio em Tangará da Serra - MT.

No segundo corte também foi observada uma regressão linear com o aumento da altura de plantas com o aumento das doses de $\mathrm{N}$, onde a maior dose utilizada $(250 \mathrm{~kg} / \mathrm{ha})$ proporcionou uma altura de plantas de $0,86 \mathrm{~m}$ (Figura $3 \mathrm{~b}$ ). No terceiro corte do capim Paiaguás, a altura de plantas atingiu o valor máximo de $0,78 \mathrm{~m}$, com $250 \mathrm{~kg} / \mathrm{ha}$ de $\mathrm{N}$ (Figura 3c). Já no quarto corte observou-se a altura de 0,67 na dose de $250 \mathrm{~kg} / \mathrm{ha}$ de N, evidenciando que a altura é influenciada linearmente pela adubação nitrogenada (Figura 3d).

Notou-se que o valor médio da altura das plantas na dose de $250 \mathrm{~kg} / \mathrm{ha}$ de $\mathrm{N}$ ficou em torno de 0,75 $\mathrm{m}$ para os quatros cortes, significando um incremento próximo a $15 \%$ quando se comparou a máxima dose de $\mathrm{N}$ utilizada com a ausência de adubação nitrogenada. Monteiro et al. (1995), omitindo nitrogênio 
em capim Marandu observaram limitação na produção de massa seca, tanto na parte aérea como nas raízes, o que refletiu na altura das plantas, corroborando com este trabalho, visto que nas doses mais baixas e na ausência de nitrogênio, o capim Paiaguás apresentou as menores alturas.

Para a variável número de perfilhos $/ \mathrm{m}^{2}(\mathrm{NP})$, no primeiro corte verificou-se diferença entre as doses de $\mathrm{N}$, onde o ponto de máxima resposta ao fertilizante foi na dose de $226,37 \mathrm{~kg} / \mathrm{ha}$ de $\mathrm{N}$, apresentando 431,11 perfilhos $/ \mathrm{m}^{2}$ (Figura 4a). No terceiro corte (Figura 4b) a regressão linear foi significativa, sendo que com a aplicação de $250 \mathrm{~kg} / \mathrm{ha}$ de $\mathrm{N}$, o número de perfilhos foi de $145 / \mathrm{m}^{2}$. Pôde-se observar que o número de perfilhos $/ \mathrm{m}^{2}$ no terceiro corte foi bem inferior ao número de perfilhos $/ \mathrm{m}^{2}$ do primeiro e quarto cortes, sendo que este resultado pode estar relacionado ao fato deste período ter apresentado a menor precipitação entre os períodos avaliados (Figura 1). Vários são os efeitos positivos que fontes de nitrogênio exercem sobre o perfilhamento das plantas forrageiras, existindo na literatura vários trabalhos destacando estes benefícios na densidade de perfilhos das pastagens (Alexandrino et al., 2010; Carard et al., 2008; Fagundes et al., 2006; Germano et al., 2018; Martuscello et al., 2005; Martuscello et al., 2006).
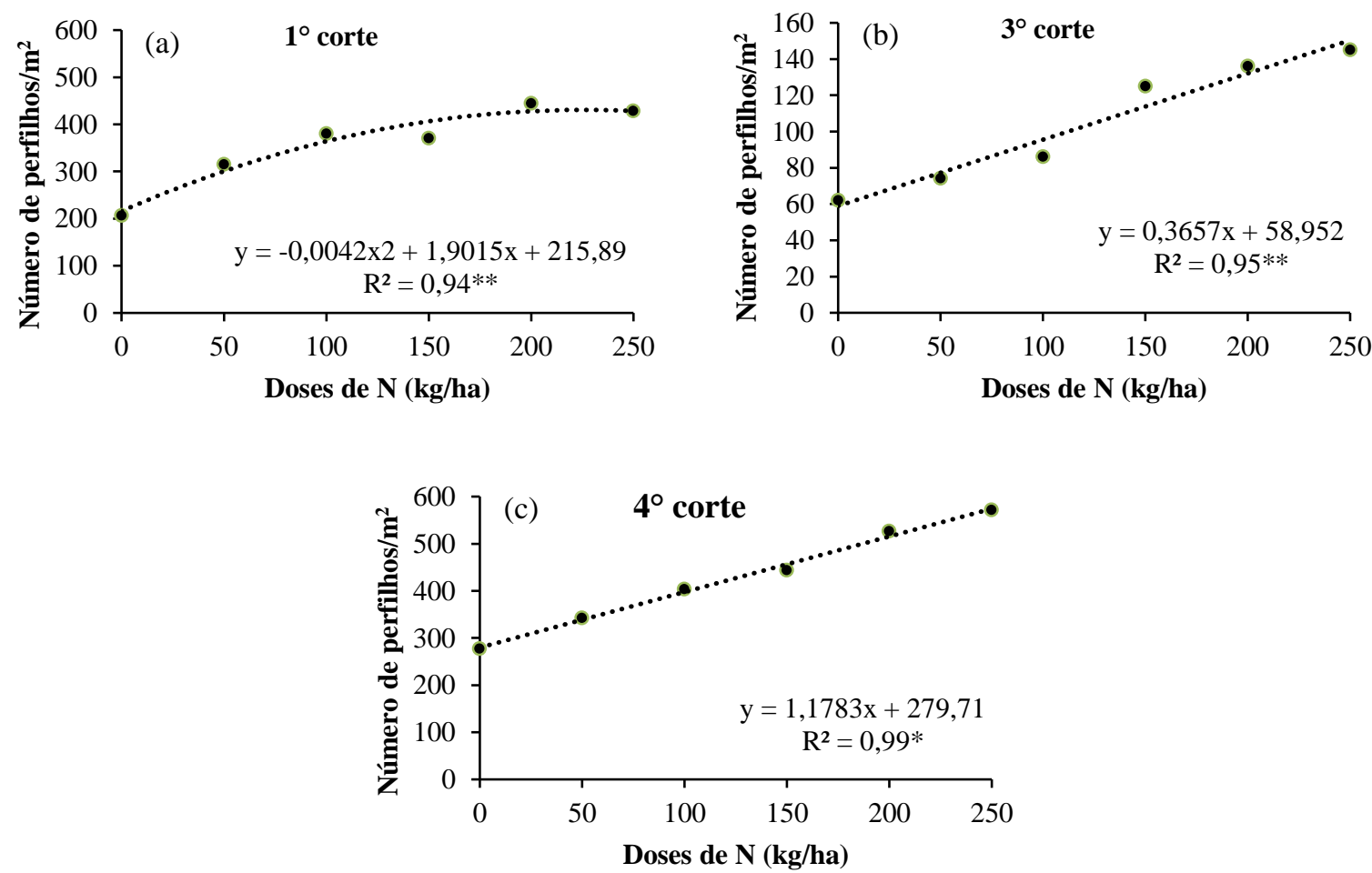

Figura 4. Número de perfilhos $/ \mathrm{m}^{2}\left(\mathrm{NP}, \mathrm{m}^{2}\right)$ no primeiro (a), terceiro (b) e quarto cortes (c) de $B$. brizantha cv. Paiaguás em diferentes doses de nitrogênio em Tangará da Serra - MT.

Santos et al. (2011) relataram que do ponto de vista da nutrição mineral, o aparecimento de perfilhos é influenciado principalmente pelo nitrogênio e pelo estádio de desenvolvimento em que a planta se encontra. Alexandrino et al. (2010), afirmaram que o nitrogênio em menores quantidades aumenta o número de gemas dormentes, ao mesmo tempo em que o seu suprimento permite um maior número de perfilhos, o que também foi observado nesta pesquisa. Já na Figura $4 \mathrm{c}$ observou-se que no quarto corte, o maior número de perfilhos ocorreu na maior dose de N (250 kg/ha), apresentando 571 perfilhos $/ \mathrm{m}^{2}$, sendo significativa a regressão linear, indicando que doses maiores de $\mathrm{N}$ podem produzir um maior número de perfilhos $/ \mathrm{m}^{2}$, aumentando a biomassa de forragem/área.

Valentine \& Matthew (1999) afirmaram que o equilíbrio entre o aparecimento e a morte de perfilhos é extremamente dependente do regime de corte ou desfolhação, onde a menor altura de corte pode prejudicar o perfilhamento e o contrário ocorre nas maiores alturas. No entanto, em estudo realizado por Benett et al. (2008), plantas forrageiras cultivadas em alturas maiores foram comprometidas, pois ocorreu uma menor entrada de luz na base das touceiras, reduzindo o estímulo de brotação das gemas basilares, diminuindo com isso, o aparecimento de novos perfilhos. 
Em relação à variável porcentagem de massa seca $(\% \mathrm{MS})$, no terceiro corte houve diferença significativa, apresentando regressão linear, com decréscimo da porcentagem de massa seca com as maiores doses de nitrogênio (Figura 5).

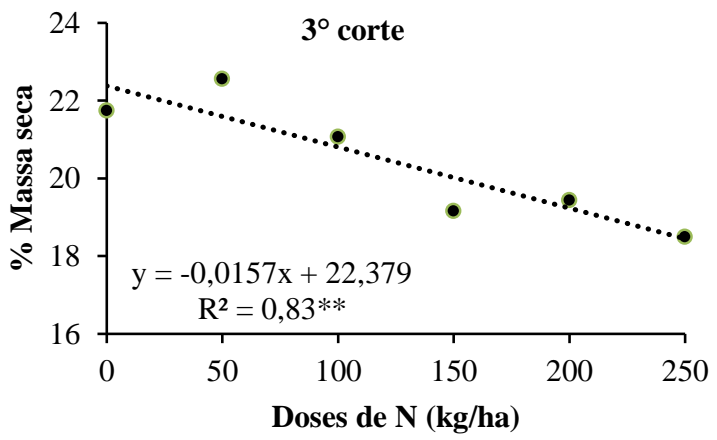

Figura 5. Porcentagem de massa seca (\%MS) no terceiro corte de B. brizantha cv. Paiaguás em diferentes doses de nitrogênio em Tangará da Serra - MT.

O decréscimo da porcentagem de massa seca em relação ao acréscimo de nitrogênio é explicado pela relação de maior quantidade de folhas e menor de colmos no rebrote, o que reduz a porcentagem de massa seca (Fontes et al., 2014). Porto (2017) obteve resultados semelhantes ao avaliar a porcentagem de massa seca em diferentes doses de nitrogênio na produtividade do capim Piatã, onde o maior valor foi sem adubação e o menor na dose de $250 \mathrm{~kg} / \mathrm{ha}$, dados semelhantes aos deste trabalho.

A Tabela 3 apresenta os valores médios de cada variável, no seu respectivo corte e se houve ou não diferença significativa nas diferentes doses de $\mathrm{N}$.

Tabela 3. Média da massa verde/ha (MV), da massa seca/ha (MS), da massa seca de folhas/ha (MSF), da massa seca de colmos/ha (MSC) e da massa seca de material senescente/ha (MSMS) de B. brizantha cv. Paiaguás em diferentes doses de nitrogênio em Tangará da Serra - MT.

\begin{tabular}{lccccc}
\hline Corte & $\begin{array}{c}\text { MV } \\
(\mathrm{kg} / \mathrm{ha})\end{array}$ & $\begin{array}{c}\text { MS } \\
(\mathrm{kg} / \mathrm{ha})\end{array}$ & $\begin{array}{c}\text { MSF } \\
(\mathrm{kg} / \mathrm{ha})\end{array}$ & $\begin{array}{c}\text { MSC } \\
(\mathrm{kg} / \mathrm{ha})\end{array}$ & $\begin{array}{c}\text { MSMS } \\
(\mathrm{kg} / \mathrm{ha})\end{array}$ \\
\hline $1^{\mathrm{o}}$ & $6316,67^{* *}$ & $996,82^{*}$ & $605,43^{*}$ & $325,16^{\mathrm{ns}}$ & $66,23^{\text {ns }}$ \\
$2^{\text {o }}$ & $2687,67^{\mathrm{ns}}$ & $678,58^{*}$ & $502,41^{*}$ & $119,50^{\mathrm{ns}}$ & $56,67^{*}$ \\
$3^{\text {o }}$ & $2013,88^{* *}$ & $481,67^{* *}$ & $432,67^{* *}$ & $46,83^{\mathrm{ns}}$ & $2,17^{\mathrm{ns}}$ \\
$4^{\text {o }}$ & $4269,83^{* *}$ & $1081,63^{\mathrm{ns}}$ & $751,93^{* *}$ & $288,73^{*}$ & $40,97^{\mathrm{ns}}$ \\
\hline
\end{tabular}

ns não significativo; ${ }^{*}$ significativo a $5 \% ;{ }^{* *}$ significativo a $1 \%$.

Verificou-se que a variável massa verde/ha (MV) obteve diferença significativa entre os tratamentos, no primeiro, terceiro e quarto cortes. A massa seca/ha (MS) não apresentou diferença significativa entre as doses de $\mathrm{N}$ somente no quarto corte. A massa seca de folhas/ha (MSF) obteve diferença significativa em todos os cortes. A massa seca de colmos/ha (MSC) apresentou diferença significativa entre as doses de $\mathrm{N}$ apenas no quarto corte e a massa seca de material senescente/ha (MSMS) apenas no segundo corte (Tabela 3). Observou-se no primeiro, terceiro e quarto cortes (Figura 6 a, b, c), que os maiores valores de massa verde/ha (MV), 9150,0; 2902,5 e 5438,0 kg/ha respectivamente foram obtidos entre 150 e 200 $\mathrm{kg} / \mathrm{ha}$, apresentando efeito linear no primeiro e terceiro cortes e efeito quadrático no quarto corte, sendo que neste, o ponto de máxima resposta ao fertilizante foi na dose de $180,99 \mathrm{~kg} / \mathrm{ha}$ de $\mathrm{N}$, apresentando um total de $5488 \mathrm{~kg} / \mathrm{ha}$ de massa verde.

Segundo Martuscello et al. (2005), o aumento na produção de forragem com a aplicação de nitrogênio é fato esperado em ensaios dessa natureza, devido ao conhecido efeito do nitrogênio no acúmulo de massa, pois o suprimento de nitrogênio é um dos fatores de manejo que controla os diferentes processos de crescimento das plantas. Souza et al. (2005), trabalhando com Panicum maximum evidenciaram que doses de nitrogênio e irrigação aumentaram a produção de massa de forragem produzida, sendo que todas as cultivares estudadas responderam à aplicação de nitrogênio. 

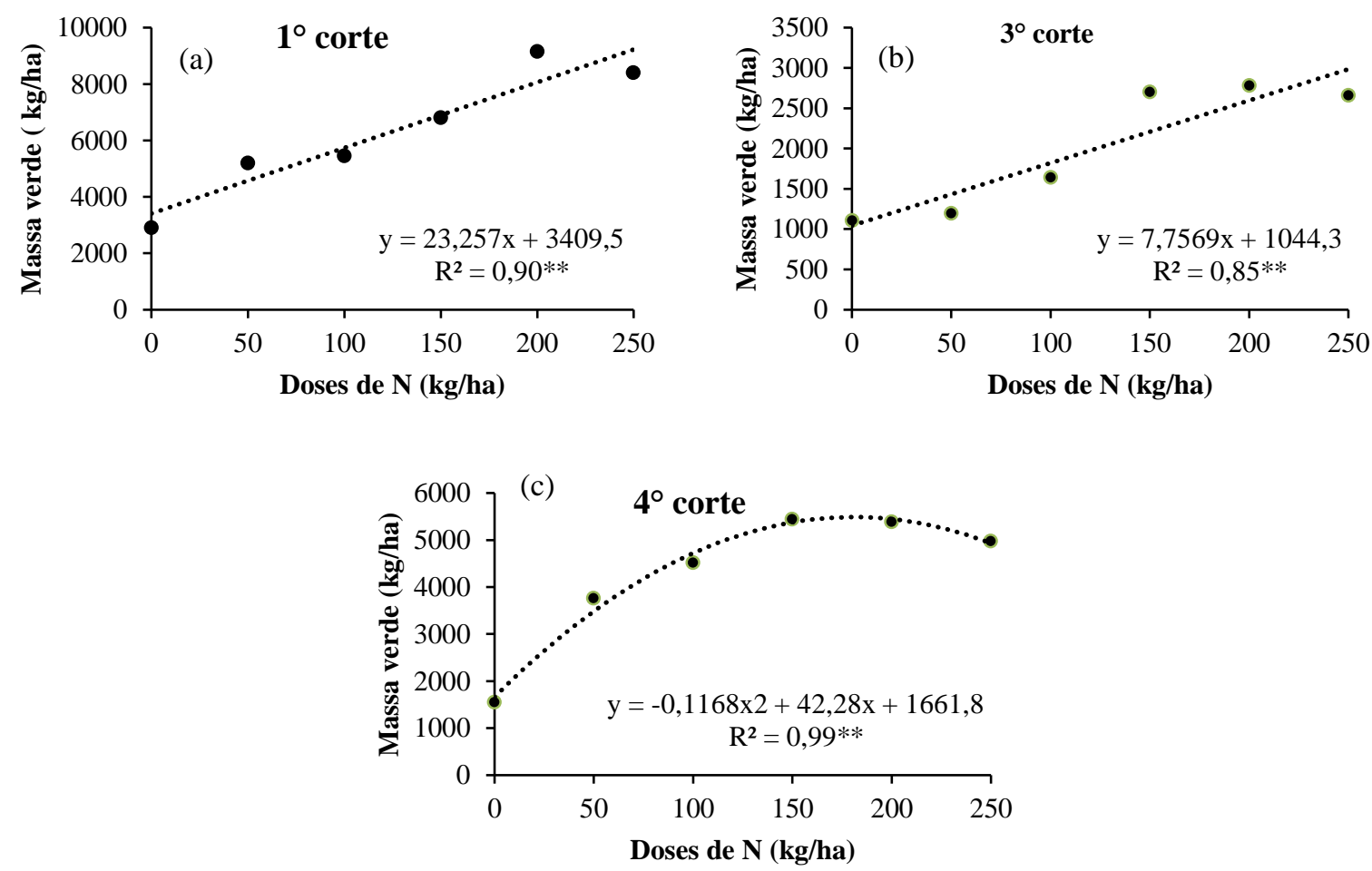

Figura 6. Massa verde/ha (MV, kg/ha) no primeiro (a), terceiro (b) e quarto cortes (c) de B. brizantha cv. Paiaguás em diferentes doses de nitrogênio em Tangará da Serra - MT.

Na Figura 7 observou-se que houve diferença significativa para a variável massa seca/ha (MS) nas diferentes doses de N, no primeiro, segundo e terceiro cortes. No primeiro corte (Figura 7a), obteve-se produção de massa seca/ha máxima $(1337,35 \mathrm{~kg} / \mathrm{ha}$ ) na dose de $200 \mathrm{~kg} / \mathrm{ha}$, podendo ser observado o efeito linear nos três cortes que apresentaram diferença significativa, indicando que nenhum dos tratamentos satisfez totalmente a necessidade da cultura, o que indica que doses maiores que $250 \mathrm{~kg} / \mathrm{ha}$ podem trazer melhores resultados para o capim Paiaguás com relação à quantidade de massa seca/ha.
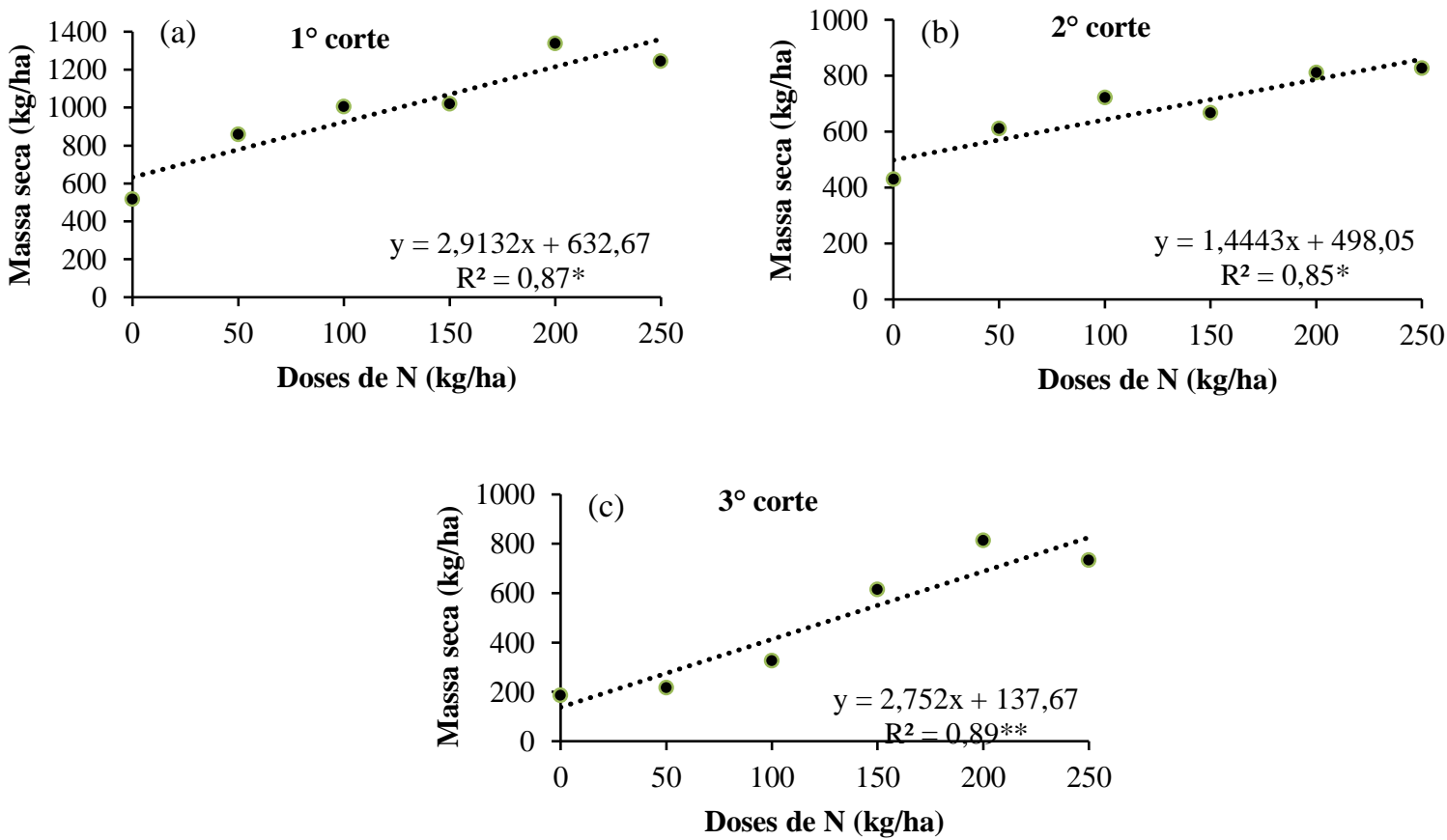

Figura 7. Massa seca/ha (MS, kg/ha) no primeiro (a), segundo (b) e terceiro cortes (c) de B. brizantha cv. Paiaguás em diferentes doses de nitrogênio em Tangará da Serra - MT. 
Existem na literatura muitos trabalhos que demonstram a correlação positiva existente entre a adubação nitrogenada e a produção de massa seca das gramíneas tropicais (Alexandrino et al., 2010; Cabral et al., 2012; Costa et al., 2014; Germano et al., 2018; Martuscello et al., 2005; Sousa et al., 2012). Esse comportamento se deve ao fato do nitrogênio promover significativo aumento das reações enzimáticas e do metabolismo das plantas, proporcionando maior teor de clorofila nas folhas, aumentando assim, a oferta de fotoassimilados que influenciam diretamente na produção de biomassa (Vitor et al., 2009).

No segundo corte (Figura 7b) observou-se o valor crescente da massa seca/ha com o aumento das doses de $\mathrm{N}$, com ápice na dose de $250 \mathrm{~kg} / \mathrm{ha}$ de $\mathrm{N}$, produzindo $827,5 \mathrm{~kg} / \mathrm{ha}$ de massa seca e o terceiro corte (Figura 7c) apresentou a produção máxima de massa seca de $813,0 \mathrm{~kg} / \mathrm{ha}$, na dose de $200 \mathrm{~kg} / \mathrm{ha}$. Fagundes et al. (2006) verificaram que o suprimento de nitrogênio no solo normalmente não atende à demanda das gramíneas, porém, quando há adubação nitrogenada são observadas grandes alterações na quantidade de massa seca.

Para a variável massa seca de folhas/ha (MSF) houve diferença significativa entre as doses de $\mathrm{N}$ nos quatro cortes, apresentando regressão linear (Figura 8). No primeiro corte, a maior quantidade de massa seca de folhas/ha (743,09 kg/ha) foi atingida na dose de $200 \mathrm{~kg} / \mathrm{ha}$ de N (Figura 8a). Silva et al. (2013), avaliando Brachiaria brizantha cv. Marandu observaram que no segundo ano de produção, a massa seca das folhas foi de $7366 \mathrm{~kg} / \mathrm{ha}$, aplicando $300 \mathrm{~kg} / \mathrm{ha} / \mathrm{ano}$ de $\mathrm{N}$, demonstrando um aumento médio de $75 \%$ em relação ao tratamento testemunha. Batista \& Monteiro (2006) avaliaram capim Marandu cultivado em vasos e adubado com doses combinadas de nitrogênio e enxofre e constataram que as maiores produções de massa seca foliar ocorreram nas doses mais elevadas de nitrogênio em combinação com enxofre, sendo a dose de nitrogênio de $350 \mathrm{mg} \mathrm{L}^{-1}$ associada às doses de enxofre de 60 a $80 \mathrm{mg} \mathrm{L}^{-1}$, a que obteve as maiores produções de massa seca de folhas.

No segundo (Figura 8 b) corte houve um efeito linear, obtendo-se a maior produção de massa seca de folhas/ha na dose de $250 \mathrm{~kg} / \mathrm{ha}$ de $\mathrm{N}$, produzindo $568 \mathrm{~kg} / \mathrm{ha}$ de massa seca de folhas. Para o terceiro corte (Figura 8c), o efeito também foi linear, onde a melhor dose foi de $200 \mathrm{~kg} / \mathrm{ha} \mathrm{de} \mathrm{N}$, apresentando $726 \mathrm{~kg} / \mathrm{ha}$ de massa seca de folhas. No quarto corte (Figura 8d) houve diferença significativa entre as doses de $\mathrm{N}$ para a massa seca de folhas/ha, com maior valor $(1129,4 \mathrm{~kg} / \mathrm{ha})$ observado na dose de 250 $\mathrm{kg} / \mathrm{ha}$.
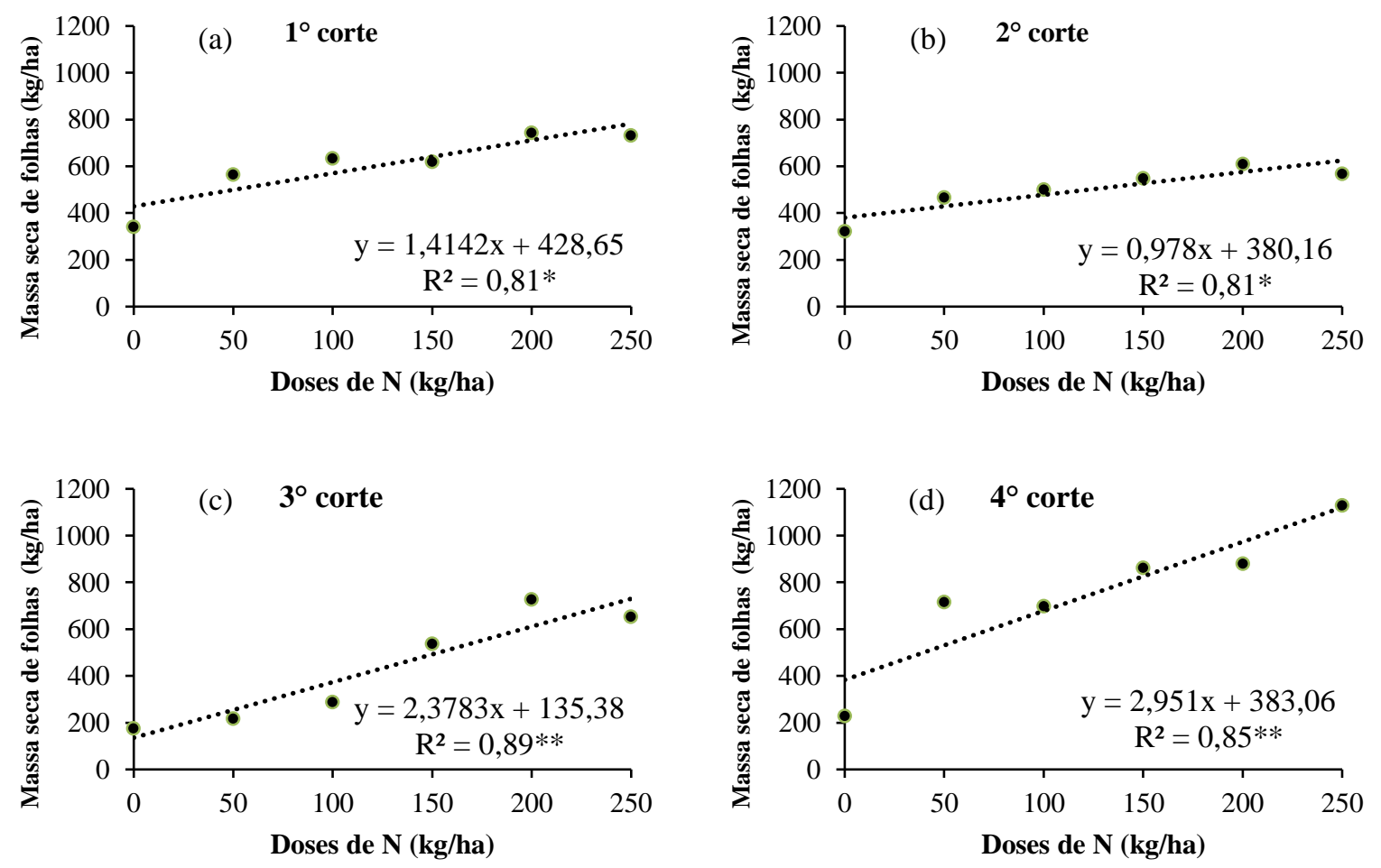

Figura 8. Massa seca de folhas/ha (MSF, kg/ha) no primeiro (a), segundo (b), terceiro (c) e quarto cortes (d) de B. brizantha cv. Paiaguás em diferentes doses de nitrogênio em Tangará da Serra-MT. 
Germano et al. (2018), avaliando a produtividade e as características agronômicas da B. brizantha cv. Paiaguás adubada com doses parceladas de nitrogênio e desfolhação realizada sob cortes, no segundo ano de produção, verificaram que no segundo e terceiro cortes, a regressão linear foi a que melhor se ajustou, observando-se uma tendência ao aumento da massa seca de folhas conforme ocorre o aumento das doses de nitrogênio, indicando que nenhum dos tratamentos atendeu plenamente a necessidade da cultura, fato este, também observado neste estudo.

Batista \& Monteiro (2006) verificaram que a produção de massa seca foliar avaliada no segundo corte apresentou respostas significativas em função das doses de nitrogênio utilizadas, com os resultados ajustando-se ao modelo quadrático, onde a máxima produção de massa seca de folhas ocorreu na dose de $369,8 \mathrm{mg} \mathrm{L}^{-1}$ de nitrogênio. Fagundes et al. (2005), avaliando aplicação de nitrogênio em Brachiaria decumbens, observaram efeito linear positivo do nitrogênio sobre a massa seca de folhas nas estações de verão, outono e inverno.

A massa seca de colmos/ha (MSC) foi influenciada positivamente pelas doses de $\mathrm{N}$ aplicadas no primeiro corte (Figura 9), apresentando um efeito linear conforme foi aumentando as doses de N. A maior resposta $(485,11 \mathrm{~kg} / \mathrm{ha}$ ) foi obtida com a dose de $200 \mathrm{~kg} / \mathrm{ha}$. De acordo com Alexandrino et al. (2004), o baixo acúmulo de massa seca de colmos nas plantas forrageiras, na ausência de adubação nitrogenada, deve-se ao menor alongamento do colmo e ao baixo perfilhamento.

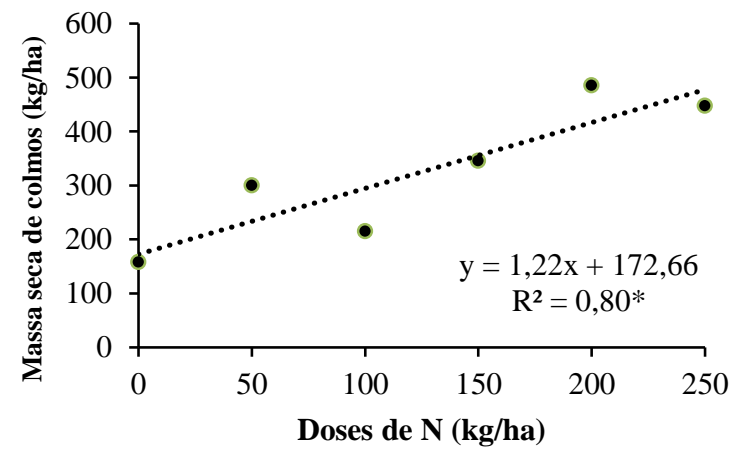

Figura 9. Massa seca de colmos/ha (MSC, kg/ha) no primeiro corte de B. brizantha cv. Paiaguás em diferentes doses de nitrogênio em Tangará da Serra - MT.

Para massa seca de material senescente/ha (MSMS), no segundo corte (Figura 10) observou-se decréscimo até a dose de $150 \mathrm{~kg} / \mathrm{h}$ a de $\mathrm{N}$ e posteriormente houve aumento dos valores até a maior dose $(250 \mathrm{~kg} / \mathrm{ha}$ ), onde foram obtidos $80,03 \mathrm{~kg} / \mathrm{ha}$ de material senescente. O ponto de mínima resposta ao fertilizante foi na dose de $119,58 \mathrm{~kg} / \mathrm{ha}$ de $\mathrm{N}$, com $42,37 \mathrm{~kg} / \mathrm{ha}$ de massa seca de material senescente.

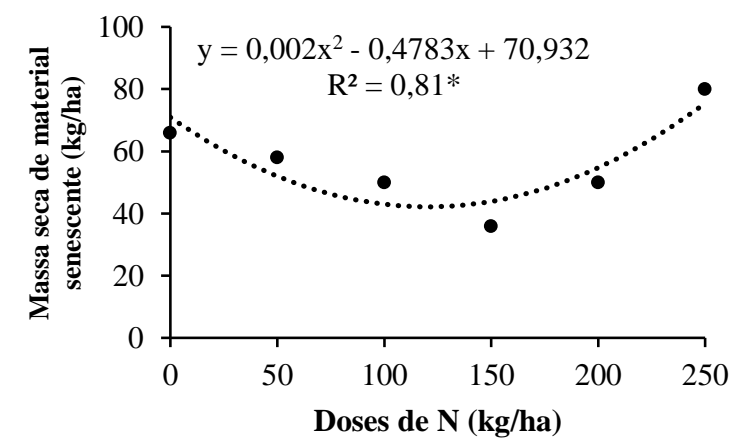

Figura 10. Massa seca de material senescente/ha (MSMS, kg/ha) no segundo corte de $B$. brizantha cv. Paiaguás em diferentes doses de nitrogênio em Tangará da Serra - MT.

A Tabela 4 apresenta a média e/ou soma dos quatro cortes, para todas as variáveis avaliadas, em cada dose de nitrogênio $(\mathrm{N})$ e se houve ou não diferença significativa entre as doses de $\mathrm{N}$. As variáveis que apresentaram diferença significativa entre os tratamentos foram média da altura de plantas (MAP), do 
número de perfilhos $/ \mathrm{m}^{2}$ (MNP), da massa seca/perfilho (MMSP) e soma dos quatro cortes de massa verde/ha (SMV), de massa seca/ha (SMS), de massa seca de folhas/ha (SMSF) e de massa seca de colmos/ha (SMSC).

Tabela 4. Média da altura de plantas (MAP), do número de perfilhos $/ \mathrm{m}^{2}$ (MNP), do número de folhas/perfilho (MNFP), da massa seca/perfilho (MMSP), da porcentagem de massa seca (\%MMS), da relação folha: colmo (MRFC), e da soma da massa verde/ha (SMV), da massa seca/ha (SMS), da massa seca de folhas/ha (SMSF), da massa seca de colmos/ha (SMSC), da massa seca de material senescente/ha (SMSMS) de B. brizantha cv. Paiaguás em diferentes doses de nitrogênio, em Tangará da Serra - MT. (Médias e somas são em relação aos quatro cortes avaliados juntos).

\begin{tabular}{|c|c|c|c|c|c|c|c|}
\hline \multirow{2}{*}{ Variáveis } & \multicolumn{6}{|c|}{ Doses de N (kg/ha) } & \multirow{2}{*}{$\begin{array}{l}\mathrm{CV} \\
(\%)\end{array}$} \\
\hline & 0 & 50 & 100 & 150 & 200 & 250 & \\
\hline$\overline{\mathrm{MAP}(\mathrm{m})}{ }^{* * *}$ & 0,31 & 0,38 & 0,45 & 0,54 & 0,66 & 0,75 & 3,12 \\
\hline $\operatorname{MNP}\left(\mathrm{m}^{2}\right)^{* *}$ & 150,25 & 205,00 & 245,50 & 259,25 & 314,50 & 308,00 & 16,67 \\
\hline $\mathrm{MNFP}^{\mathrm{ns}}$ & 4,22 & 4,36 & 4,55 & 4,18 & 4,23 & 4,22 & 5,72 \\
\hline $\operatorname{MMSP}(\mathrm{g})^{* *}$ & 0,58 & 0,55 & 0,58 & 0,65 & 0,67 & 0,80 & 12,03 \\
\hline$\% \mathrm{MMS}^{\mathrm{ns}}$ & 21,27 & 23,10 & 23,80 & 20,97 & 25,09 & 23,67 & 9,73 \\
\hline $\mathrm{MRFC}^{\mathrm{ns}}$ & 2,60 & 2,82 & 4,13 & 4,21 & 3,88 & 3,46 & 39,96 \\
\hline $\operatorname{SMV~}(\mathrm{kg} / \mathrm{ha})^{* *}$ & 7152 & 12747 & 14355 & 17939 & 20497 & 18926 & 16,93 \\
\hline SMS (kg/ha) ${ }^{* *}$ & 1469 & 2847 & 3286 & 3602 & 4587 & 4143 & 19,57 \\
\hline SMSF $(\mathrm{kg} / \mathrm{ha})^{* *}$ & 995 & 2003 & 2421 & 2547 & 3337 & 2832 & 21,34 \\
\hline $\operatorname{SMSC}(\mathrm{kg} / \mathrm{ha})^{* *}$ & 343 & 649 & 674 & 932 & 1128 & 1076 & 24,54 \\
\hline SMSMS (kg/ha) ${ }^{n s}$ & 131 & 195 & 190 & 123 & 122 & 235 & 39,70 \\
\hline
\end{tabular}

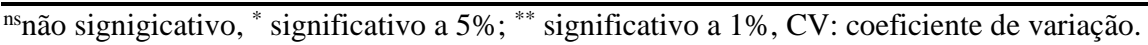

Nas Figuras 11 e 12, podem-se verificar as médias dos quatro cortes de cada variável significativa. Observou-se que para a média da altura de plantas (MAP) dos quatro cortes (Figura 11a), o valor foi crescente, atingindo $0,75 \mathrm{~m}$ na dose de $250 \mathrm{~kg} / \mathrm{ha}$ de N. Pompeu et al. (2010), ao avaliarem as características morfofisiológicas do capim Aruana sob regime de cortes com três doses de adubação nitrogenada $\left(125,250\right.$ e $\left.375 \mathrm{mg} \mathrm{de} \mathrm{N} / \mathrm{dm}^{3}\right)$ obtiveram incrementos positivos na altura das plantas, devido à maior disponibilidade de nitrogênio no solo e sua consequente absorção pelas plantas, acelerando o crescimento dos tecidos, com reflexo na altura das plantas.
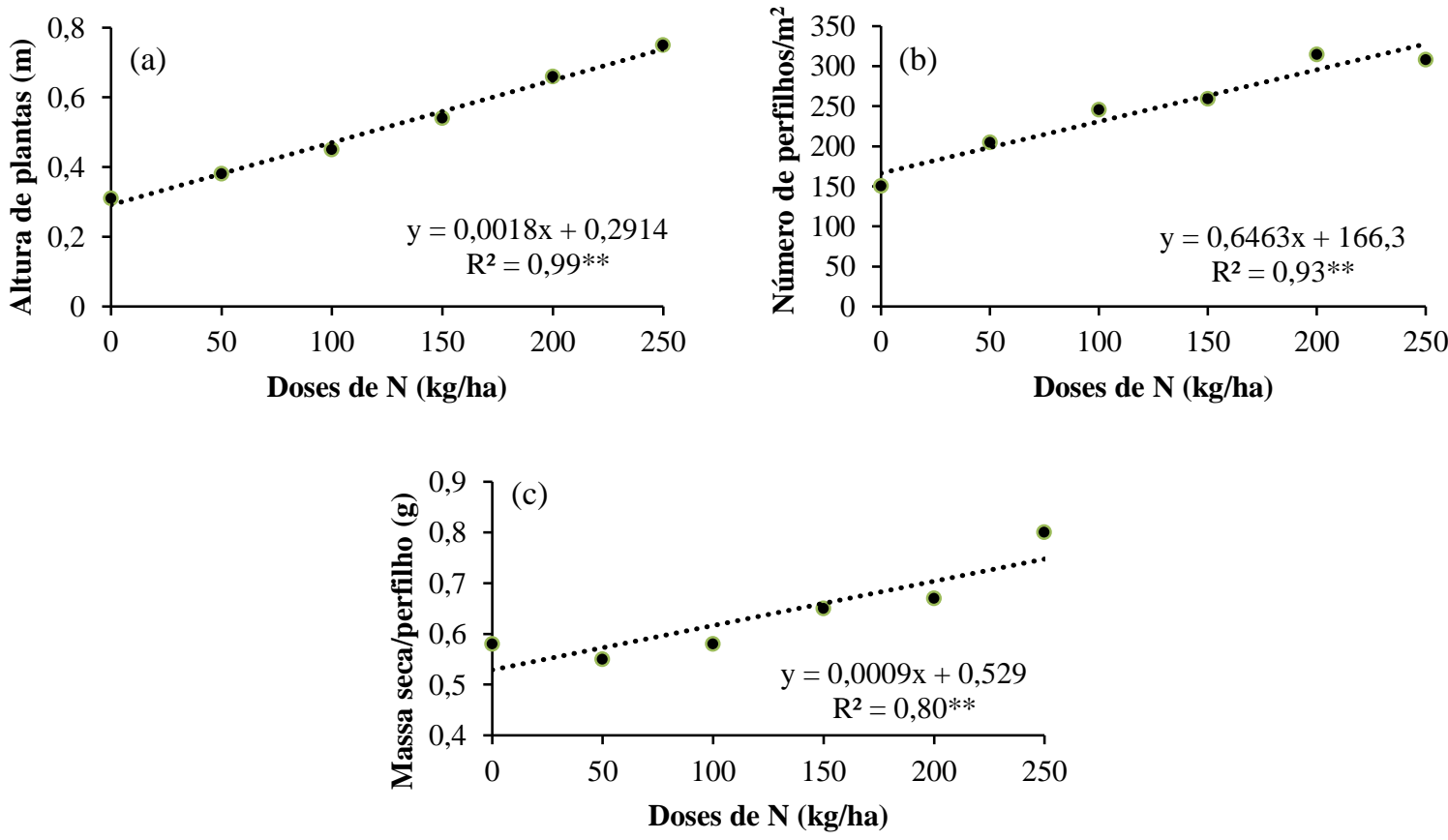

Figura 11. Média da altura de plantas (MAP, m) (a), do número de perfilhos $/ \mathrm{m}^{2}\left(\mathrm{MNP}, \mathrm{m}^{2}\right)$ (b) e da massa seca/perfilho (MMSP, g) (c) de B. brizantha cv. Paiaguás em diferentes doses de nitrogênio em Tangará da Serra - MT. (A média é em relação aos quatro cortes avaliados juntos). 
Em relação à média do número de perfilhos $/ \mathrm{m}^{2}$ (MNP) dos quatro cortes (Figura 11b) constatou-se que houve aumento no número de perfilhos com as doses crescentes de $\mathrm{N}$, sendo que a dose de 200 $\mathrm{kg} /$ ha de $\mathrm{N}$ apresentou a maior média de perfilhos, produzindo 314,50 perfilhos $/ \mathrm{m}^{2}$. Cabral et al. (2012), quando avaliaram o capim Xaraés adubado com as doses de $0,125,250,375,500 \mathrm{~kg} / \mathrm{ha}$ de N, encontraram um efeito quadrático das doses de nitrogênio sobre a densidade populacional de perfilhos, sendo encontrado o maior perfilhamento para a dose de $270 \mathrm{~kg} / \mathrm{ha}$ de $\mathrm{N}$, semelhante ao encontrado neste estudo. De acordo com Alexandrino et al. (2010), a quantidade de perfilhos/área é um dos principais componentes que vai definir a produção de massa seca das pastagens, gerando assim uma alta produtividade da cultura, corroborando com os resultados encontrados neste estudo, em que houve um aumento no número de perfilhos $/ \mathrm{m}^{2}$ com o aumento das doses de $\mathrm{N}$.

Para a média dos quatro cortes da massa seca/perfilho (MMSP), o crescimento linear também foi observado (Figura 11c), com maior massa seca/perfilho (0,83 g) na dose de $250 \mathrm{~kg} / \mathrm{ha}$. Silva et al. (2013) em condições de campo, obtiveram maior massa seca de perfilhos do capim Marandu com a dose de $376 \mathrm{~kg} / \mathrm{ha}$ de $\mathrm{N}$.

Na Figura 12a observou-se o efeito positivo da adubação nitrogenada na soma da massa verde/ha (SMV) dos quatro cortes, com o ponto de máxima resposta ao fertilizante na dose de $232,01 \mathrm{~kg} / \mathrm{ha}$ de $\mathrm{N}$, apresentando um total de 19557,61 kg/ha de massa verde, diferindo dos dados encontrados por Orrico Junior et al. (2013) que encontraram maior produção de massa verde e seca na dose de $300 \mathrm{~kg}$ de $\mathrm{N} / \mathrm{ha} /$ corte, quando os mesmos compararam com a produção da dose inicial de $100 \mathrm{~kg}$ de N/ha/corte.

$\mathrm{Na}$ Figura 12b, a soma dos quatro cortes da variável massa seca/ha (SMS), apresentou o ponto de máxima resposta na dose de 234,05 kg/ha de $\mathrm{N}$, produzindo um total de $4271,19 \mathrm{~kg} / \mathrm{ha}$ de massa seca. Chagas \& Botelho (2005), avaliando o efeito de doses de nitrogênio no desempenho inicial de Brachiaria decumbens cv. Basilisk em relação à produção de massa seca e teor de proteína bruta observaram efeito na produção de massa seca em função de doses de nitrogênio, onde aos 105 dias após o plantio, a melhor dose para a produção de massa seca foi de $104 \mathrm{~kg} / \mathrm{ha}$ de $\mathrm{N}$.

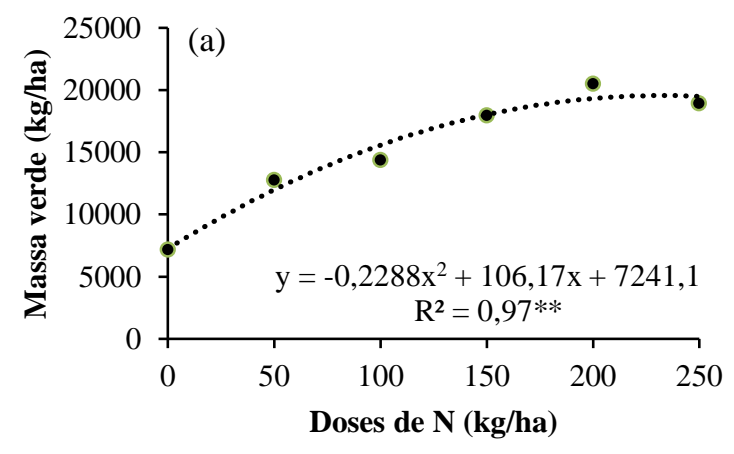

(b)
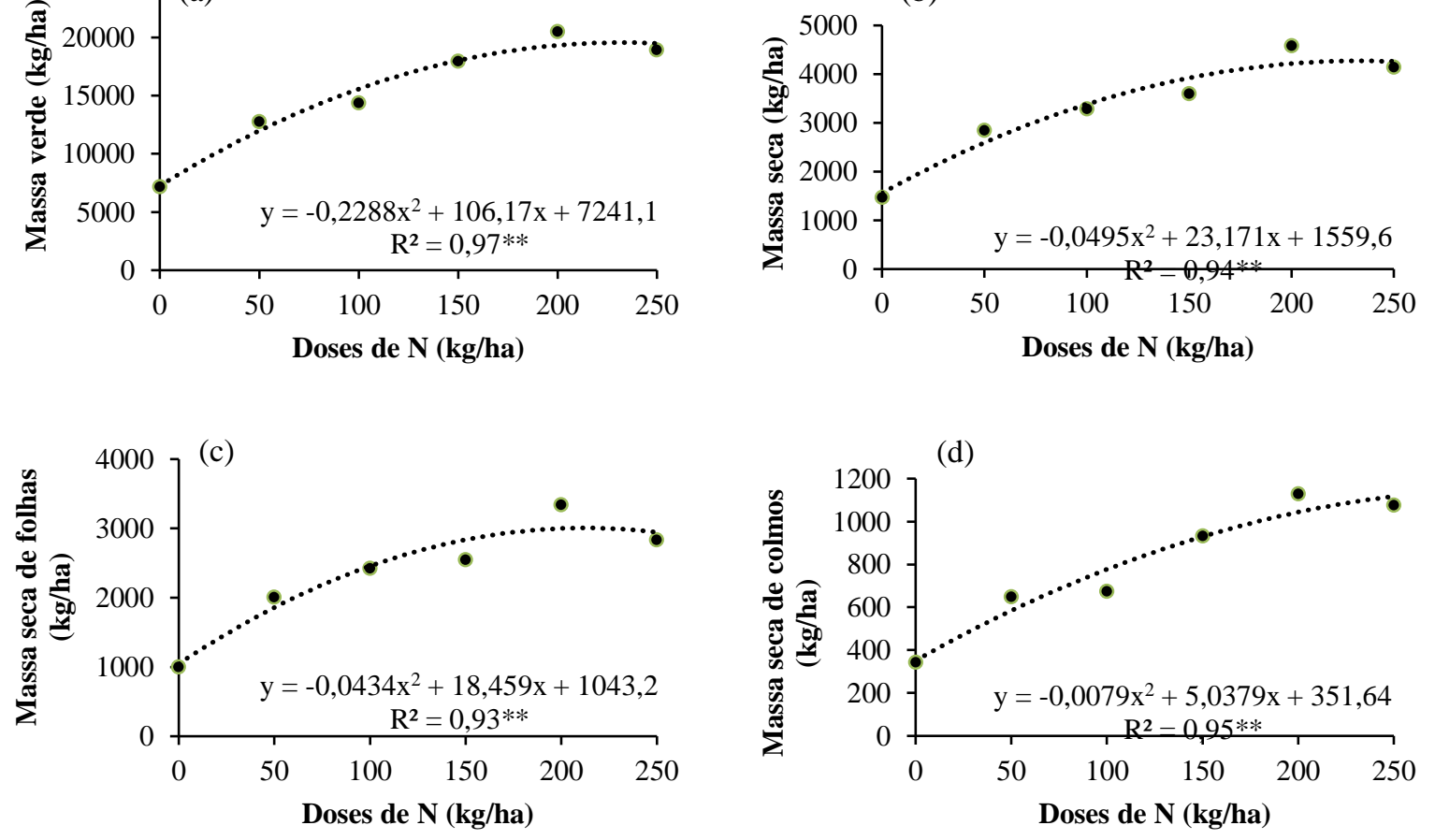

Figura 12. Soma da massa verde/ha (SMV, kg/ha) (a), da massa seca/ha (SMS, kg/ha) (b), da massa seca de folhas/ha (SMSF, $\mathrm{kg} / \mathrm{ha}$ ) (c) e da massa seca de colmos/ha (SMSC, kg/ha) (d) de B. brizantha cv. Paiaguás em diferentes doses de nitrogênio em Tangará da Serra - MT. (A soma é em relação aos quatro cortes avaliados juntos). 
Para a soma da massa seca de folhas/ha (SMSF) dos quatro cortes (Figura 12c) foi verificada regressão quadrática, onde a melhor dose de $\mathrm{N}$ foi de $212,67 \mathrm{~kg} / \mathrm{ha}$ e produziu $3005,96 \mathrm{~kg} / \mathrm{ha}$ de massa seca de folhas. Andrade et al. (2010), trabalhando com capim Marandu, constataram acréscimo na massa seca de folhas com o aumento das doses de N, condizendo com os resultados obtidos neste trabalho. Germano et al. (2018), avaliando doses de nitrogênio sob diferentes cortes em B. brizantha cv. Paiaguás verificaram, para a massa seca de folhas/ha, um efeito significativo quadrático na soma dos quatro cortes, observando na dose de 202,09 kg/ha de N, uma produção de 3943,73 kg/ha de massa seca de folhas.

Na Figura 12 d observou-se efeito positivo das doses de $\mathrm{N}$ sobre a massa seca de colmos/ha (SMSC), onde a máxima produção encontrada foi de $1154,82 \mathrm{~kg} / \mathrm{ha}$, quando foi utilizada a dose de $318,85 \mathrm{~kg} / \mathrm{ha}$ de N. Doses elevadas para a máxima produção de massa seca de colmos também foram constatadas em trabalho realizado por Bonfim-Silva \& Monteiro (2006), que adubando capim Marandu em solução nutritiva, observaram o maior valor no primeiro corte, na dose de nitrogênio de 404,6 mg/L. O nitrogênio induz processos metabólicos que resultam em efeitos marcantes na produção de massa seca e energia para gramíneas e leguminosas forrageiras, provocando o crescimento diferenciado de órgãos e sistemas (Cecato et al., 2000). Este nutriente promove alterações nas emissões de perfilhos e folhas e consequentemente modifica a produção de massa seca, além de ser o nutriente que mais favorece alterações no comprimento, na superfície e na massa seca do sistema radicular (Mazza et al., 2009; Viana et al., 2011).

\section{Conclusões}

As doses de nitrogênio incrementam significativamente as características produtivas da $B$. brizantha cv. Paiaguás, no terceiro ano de produção.

A dose de $200 \mathrm{~kg} / \mathrm{ha}$ de $\mathrm{N}$ apresenta os melhores resultados na maioria das variáveis estudadas.

\section{Referências bibliográficas}

Alexandrino, E., Nascimento Junior, D. do, Mosquim, P. R., Regazzi, A. J. \& Rocha, F. C. (2004). Características morfogênicas e estruturais na rebrotação da Brachiaria brizantha cv. Marandu submetida a três doses de nitrogênio. Revista Brasileira de Zootecnia, 33(6):1372-1379.

Alexandrino, E., Vaz, R. G. M. V. \& Santos, A. C. (2010). Características da Brachiaria brizantha cv. Marandu durante o seu estabelecimento submetida a diferentes doses de nitrogênio. Bioscience Journal, 26(6):886-893.

Andrade, A. C., Rodrigues, B. H. N., Magalhães, J. A., Souza Carneiro, M. S., Lucena Costa, N., Seixas Santos, F. J. \& Bezerra, E. E. A. (2010). Teores de proteína bruta, fibra em detergente neutro e fibra em detergente ácido de gramíneas forrageiras sob irrigação e nitrogênio em Parnaíba, Piauí. PubVet, 4(28):899.

Batista, K. \& Monteiro, F. A. (2006). Respostas morfológicas e produtivas do capim-marandu adubado com doses combinadas de nitrogênio e enxofre. Revista Brasileira de Zootecnia, 35(4):1281-1288.

Benett, C. G. S., Yamashita, O. M., Koga, P. S. \& Silva, K. S. (2008). Resposta da Brachiaria brizantha cv. Marandu a diferentes tipos de adubação. Revista de Ciências Agro-Ambientais, 6(1):13-20.

Bonfim-Silva, E. M. \& Monteiro, F. A. (2006). Nitrogênio e enxofre em características produtivas do capimbraquiária proveniente de área de pastagem em degradação. Revista Brasileira de Zootecnia, 35(4):1289-1297.

Brighenti, A. M., Souza Sobrinho, F., Rocha, W. S. D., Martins, C. E., Demartini, D. \& Costa, T. R. (2012). Suscetibilidade diferencial de espécies de braquiária ao herbicida glifosato. Pesquisa Agropecuária Brasileira, 46(10):1241-1246.

Cabral, W. B., Souza, A. L., Alexandrino, E., Toral, F. L. B., Santos, J. N. \& Carvalho, M. V. P. (2012). Características estruturais e agronômicas da Brachiaria brizantha cv. Xaraés submetida a doses de nitrogênio. Revista Brasileira de Zootecnia, 41(4):846-855.

Cano, C. C. P., Cecato, U., Canto, M. W., Santos, G. T., Galbeiro, S., Martins, E. N. \& Mira, R. T. (2004). Nutritive value of Tanzania grass (Panicum maximum Jacq.cv. Tanzânia-1) grazed at different heights. Revista Brasileira de Zootecnia, 33(6 SUPPL. 2):1959-1968. 
Carard, M., Neres, M. A. \& Tonello, C. L. (2008). Efeito de doses crescentes de nitrogênio no desenvolvimento de cultivares de Brachiaria brizantha. Revista da FZVA, 15(2):135-144.

Cecato, U., Castro, C. R. C., Canto, M. W., Peternelli, M., Almeida Júnior, J., Jobim, C. C. \& Cano, C. C. P. (2001). Perdas de forragem em capim-Tanzânia (Panicum maximum Jacq. cv. Tanzânia-1) manejado sob diferentes alturas sob pastejo. Revista Brasileira de Zootecnia, 30(2):295-301.

Cecato, U., Yanaka, F. Y., Brito Filho, M. R. T., Santos, G. T., Canto, M. W., Onorato, W. M. \& Peternelli, M. (2000). Influência da adubação nitrogenada e fosfatada na produção, na rebrota e no perfilhamento do capim-marandu (Brachiaria brizantha [Hochst] Stapf. cv. Marandu). Acta Scientiarum. Animal Sciences, 22817-822.

Chagas, L. A. C. \& Botelho, S. M. S. (2005). Teor de proteína bruta e produção de massa seca do capimbraquiária sob doses de nitrogênio. Bioscience Journal, 21(1):35-40.

Costa, C. A. A., Andrade, A. C., Magalhães, J. A., Mehl, H. U., Rodrigues, B. H. N., da Silva, E. M. \&. Costa, N. L. (2014). Características agronômicas dos capins Digitaria sp. e Cynodon dactylon cv. Tifton-85 sob diferentes alturas de resíduo. PubVet, 7(1):1509.

Dallacort, R., Araujo Martins, J., Hiroko Inoue, M., Lourenço de Freitas, P. S. \& Junior Coletti, A. (2011). Distribuição das chuvas no município de Tangará da Serra, médio norte do Estado de Mato Grosso, Brasil. Acta Scientiarum. Agronomy, 33(2):193-200.

Euclides, V. P. B., Euclides Filho, K., De Arruda, Z. J. \& Figueiredo, G. R. (1998). Desempenho de novilhos em pastagens de Brachiaria decumbens submetidos a diferentes regimes alimentares. Revista Brasileira de Zootecnia, 27(2):246-254.

Fagundes, J. L., Fonseca, D., Mistura, C., Morais, R., Vitor, C. M. T., Gomide, J. A., . . . Costa, L. (2006). Características morfogênicas e estruturais do capim-braquiária em pastagem adubada com nitrogênio avaliadas nas quatro estações do ano. Revista Brasileira de Zootecnia, 35(1):21-29.

Fagundes, J. L., Fonseca, D. M., Gomide, J. A., Nascimento Junior, D., Vitor, C. M. T., Morais, R. V., ... Martuscello, J. A. (2005). Acúmulo de forragem em pastos de Brachiaria decumbens adubados com nitrogênio. Pesquisa Agropecuária Brasileira, 40(4):397-403.

Fontes, J. G. G., Fagundes, J. L., Backes, A. A., Barbosa, L. T., Cerqueira, E. S. A., Silva, L. M., . . . Vieira, J. S. (2014). Herbage accumulation in Brachiaria brizantha cultivars submitted to defoliation intensities. Semina: Ciências Agrárias, 35(3):1425-14838.

Germano, L. H. E., Vendruscolo, M. C., Daniel, D. F. \& Dalbianco, A. B. (2018). Produtividade e características agronômicas de Brachiaria brizantha cv. Paiaguás submetida a doses de nitrogênio sob cortes. Boletim da Indústria Animal, 751-14.

Martuscello, J. A., Fonseca, D., Nascimento Júnior, D., Santos, P., Ribeiro Júnior, J., Cunha, D. \& Moreira, L. d. M. (2005). Características morfogênicas e estruturais do capim-xaraés submetido à adubação nitrogenada e desfolhação. Revista Brasileira de Zootecnia, 34(5):1475-1482.

Martuscello, J. A., Fonseca, D. M., Nascimento Júnior, D., Santos, P. M., Cunha, D. N. F. V. \& Moreira, L. M. (2006). Características morfogênicas e estruturais de capim-massai submetido a adubação nitrogenada e desfolhação. Revista Brasileira de Zootecnia, 35(3):665-671.

Mazza, L. M., Pôggere, G. C., Ferraro, F. P., Ribeiro, C. B., Cherobim, V. F., Motta, A. C. V. \& Moraes, A. G. (2009). Adubação nitrogenada na produtividade e composição química do capim Mombaça no primeiro planalto paranaense. Scientia Agraria, 10(4):257-265.

Monteiro, F. A., Ramos, A. K. B., Carvalho, D. D., Abreu, J. B. R., Daiub, J. A. S., Silva, J. E. P. \& Natale, W. (1995). Cultivo de Brachiaria brizantha Stapf. cv. Marandu em solução nutritiva com omissões de macronutrientes. Scientia Agricola, 52(1):135-141.

Orrico Junior, M. A. P., Orrico, A. C. A., Centurion, S. R., Sunada, N. S., Vargas Júnior, S. F. M. \& Junior, F. M. V. (2013). Características morfogênicas do capim-piatã submetido à adubação com efluentes de abatedouro avícola. Ciência Rural, 43(1).

Pimenta, L. (2009). Capim novo a caminho. Revista ABCZ, 5018-20.

Pompeu, R. C. F. F., Cândido, M. J. D., Lopes, M. N., Gomes, F. H. T., Lacerda, C. F., Aquino, B. F. \& Magalhães, J. A. (2010). Características morfofisiológicas do capim-aruana sob diferentes doses de nitrogênio. Revista Brasileira de Saúde e Produção Animal, 11(4):1187-1210. 
Porto, E. M. V. (2017). Produção de biomassa de três cultivares do gênero Brachiaria spp. submetidos à adubação nitrogenada. Agropecuária Científica no Semiárido, 13(1):9-14.

Prado, I. N. (2010). Produção de bovinos de corte e qualidade da carne (Vol. 1). Maringá, Paraná, Brasil: Eduem.

Primavesi, A. C., Primavesi, O., Corrêa, L. A., Cantarella, H., Silva, A., Freitas, A. \& Vivaldi, L. J. (2004). Adubação nitrogenada em capim-coastcross: efeitos na extração de nutrientes e recuperação aparente do nitrogênio. Revista Brasileira de Zootecnia, 33(1):68-78.

Primavesi, A. C., Primavesi, O., Corrêa, L. d. A., Silva, A. G. d. \& Cantarella, H. (2006). Nutrientes na fitomassa de capim-marandu em função de fontes e doses de nitrogênio. Ciência e Agrotecnologia, 30(3):562-568.

Rezende, P. L. P., Restle, J., Fernades, J. J. R., Pádua, J. T., Neto, M. D. F. \& da Rocha, F. M. (2011). Desempenho e desenvolvimento corporal de bovinos leiteiros mestiços submetidos a níveis de suplementação em pastagem de Brachiaria brizantha. Ciência Rural, 41(8):1453-1458.

Santos, M. E. R., Fonseca, D. M., Santos, T. G. B., Silva, S. P., Gomes, V. M. \& Silva, G. P. (2011). Morphogenic and structural characteristics of tillers on areas with signalgrass pasture varying on height. Revista Brasileira de Zootecnia, 40(3):535-542.

Silva, D. R. G., Costa, K. A. P., Faquin, V., Oliveira, I. P. \& Bernades, T. F. (2013). Doses e fontes de nitrogênio na recuperação das características estruturais e produtivas do capim-marandu. Revista Ciência Agronômica, 44(1):184-191.

Silva, F. A. S. 2014. Assistat: Versão 7.7 beta. DEAG-CTRN-UFCG - Atualizado em 01 de abril de 2014. Acesso em: 15 set. 2018.

Sousa, A. R., Andrade, A. C., Magalhães, J. A., Mehl, H. U., Rodrigues, B. H. N., Silva, E. M., . . . Lucena Costa, N. (2012). Produtividade do Capim-Marandu sob diferentes doses de nitrogênio. PubVet, 7(5):1510.

Souza, É. M., Isepon, O. J., Alves, J. B., Bastos, J. F. P. \& Lima, R. C. (2005). Efeitos da irrigação e adubação nitrogenada sobre a massa de forragem de cultivares de Panicum maximum Jacq. Revista Brasileira de Zootecnia, 341146-1155.

Valentine, I. \& Matthew, C. (1999). Plant growth, development and yield. In J. White \& J. Hodgson (Eds.), New Zealand pasture and crop science. Auckland, New Zealand: Oxford University Press.

Viana, M. C. M., Freire, F. M., Ferreira, J. J., Macêdo, G. A. R., Cantarutti, R. B. \& Mascarenhas, M. (2011). Adubação nitrogenada na produção e composição química do capim-braquiária sob pastejo rotacionado. Revista Brasileira de Zootecnia, 40(7):1497-1503.

Vitor, C. M. T., Fonseca, D. d., Cóser, A. C., Martins, C. E., Nascimento Júnior, D. \& Ribeiro Júnior, J. (2009). Produção de matéria seca e valor nutritivo de pastagem de capim-elefante sob irrigação e adubação nitrogenada. Revista Brasileira de Zootecnia, 38(3):435-442.

Recebido: 5 de abril, 2019.

Aprovado: 13 de maio, 2019.

Publicado: 29 de maio, 2019.

Licenciamento: Este artigo é publicado na modalidade Acesso Aberto sob a licença Creative Commons Atribuição 4.0 (CC-BY 4.0), a qual permite uso irrestrito, distribuição, reprodução em qualquer meio, desde que o autor e a fonte sejam devidamente creditados 